\title{
TWEAK promotes endothelial progenitor cell vasculogenesis to alleviate acute myocardial infarction via the Fn14-NF-кB signaling pathway
}

\author{
ZULONG SHENG, CHENWEI JU, BING LI, ZHONGPU CHEN, XIAODONG PAN, \\ GAOLIANG YAN, YANRU HE, YUYU YAO and GENSHAN MA
}

Department of Cardiology, Zhongda Hospital, Medical School of Southeast University, Nanjing, Jiangsu 210009, P.R. China

Received December 17, 2017; Accepted May 25, 2018

DOI: $10.3892 /$ etm.2018.6703

\begin{abstract}
Acute myocardial infarction (AMI) remains one of the leading causes of mortality worldwide; however, endothelial progenitor cell (EPC) transplantation has been proposed as a promising treatment strategy for EPC. High levels of tumor necrosis factor-related weak inducer of apoptosis (TWEAK) have been reported in AMI, although its effect on EPCs has not been reported. In the present study, immunofluorescence and flow cytometry were performed to assess the effect of TWEAK in isolated mouse EPCs. Echocardiography was used to evaluate the cardiac function of murine hearts following EPC treatment in the AMI model, while collagen synthesis within the heart tissue was assessed using Masson's trichrome staining. A tube formation assay and Transwell migration assay were performed to investigate the effects of TWEAK on vessel formation and EPC migration in vitro. Angiogenesis and arteriogenesis were assessed in vivo using immunohistochemistry and western blotting was performed to determine the effect of TWEAK-mediated nuclear factor $(\mathrm{NF})-\kappa \mathrm{B}$ pathway activation in EPCs. The results revealed that TWEAK promotes EPC migration, tube formation and viability in vitro. Furthermore, TWEAK treatment resulted in improved cardiac function, decreased heart collagen and vasculogenesis in mice with AMI, which was mediated by the TWEAK- fibroblast growth factor-inducible 14 (Fn14)-NF- $\kappa \mathrm{B}$ signaling pathway, as determined using Fn14 small interfering (si)RNA and Bay 11-7082 (an $\mathrm{NF}-\kappa \mathrm{B}$ inhibitor). In summary, the results of the present study suggest that activation of the TWEAK-Fn14-NF- $\kappa$ B signaling pathway exerts a beneficial effect on EPCs for the treatment of AMI.
\end{abstract}

Correspondence to: Dr Zulong Sheng, Department of Cardiology, Zhongda Hospital, Medical School of Southeast University, 87 Dingjiaqiao Road, Nanjing, Jiangsu 210009, P.R. China

E-mail: shengzulong@126.com

Key words: tumor necrosis factor-related weak inducer of apoptosis, endothelial progenitor cells, acute myocardial infarction, nuclear factor- $\kappa \mathrm{B}$ signal, vasculogenesis

\section{Introduction}

Acute myocardial infarction (AMI) is a serious disease with high morbidity and mortality rates, affecting $>7$ million individuals around the world each year (1). Novel treatment strategies including coronary intervention technologies and the use of anticoagulant agents, antiplatelet agents, nitroglycerin receptor blockers and angiotensin receptor blockers, have been demonstrated to decrease the acute phase mortality of AMI (2); however, the prevalence of chronic heart failure in patients with AMI has increased and the long-term mortality of patients post-AMI remains high (3). Endogenous heart regeneration, including cardiomyocyte proliferation, resident stem cell niches, neovascularization, inflammation and extracellular matrix remodeling, are potential novel pathways that may stimulate repair following AMI (4).

Endothelial progenitor cells (EPCs) located in bone marrow primarily express cluster of differentiation (CD)34, CD133 and kinase domain receptors (KDR) (5). These cells may be exported to the peripheral blood and undergo differentiation into endothelial cells to support vascular endothelial repair and angiogenesis, which may be associated with cytokine gradients (6). Due to their potential to repair and regenerate vascular tissue, EPCs have been postulated as a potential treatment to improve cardiovascular disease (7).

Tumor necrosis factor (TNF)-related weak inducer of apoptosis (TWEAK) is a member of the TNF ligand superfamily and acts by binding to fibroblast growth factor-inducible 14 (Fn14), the sole receptor of TWEAK, to initiate several intracellular signaling pathways, including nuclear factor- $\mathrm{\kappa B}$ (NF- $\mathrm{kB})(5,8)$. TWEAK is expressed at low levels in healthy normal tissues; however, it is overexpressed following tissue injury, which may contribute to cancer, chronic autoimmune diseases and acute ischemic stroke $(8,9)$. TWEAK stimulates cancer cell proliferation, migration and resistance to chemotherapeutic agents (10). Furthermore, the expression of pro-angiogenic and pro-inflammatory cytokines is enhanced upon TWEAK/Fn14 activation (11). TWEAK/Fn14 signaling also serves a protective role against intestinal inflammation and prevents colitis-associated cancer via its proapoptotic effects (12). Compared with healthy individuals, soluble TWEAK is significantly elevated in patients with acute MI 
(AMI) (13). Thus, TWEAK/Fn14 have been suggested as potential mediators of cardiovascular disease and potential treatment targets (14).

The aim of the present study was to determine the effects of TWEAK on EPCs in AMI. The results demonstrated that TWEAK promotes EPC viability, migration and differentiation, providing protection against further cardiac injury in mice with AMI. It was also revealed that TWEAK is associated with the activation of the NF- $\mathrm{NB}$ signaling pathway.

\section{Materials and methods}

Reagents. Endothelial cell basal medium-2 (EBM-2) and endothelial cell growth medium-2 (EGM-2) were purchased from Lonza Group, Ltd. (Basel, Switzerland). Human TWEAK (cat. no. RAB1765) and Mouse TWEAK (cat. no. RAB0495) ELISA kits were purchased from Sigma-Aldrich; Merck KGaA (Darmstadt, Germany). Matrigel Matrix, and rat anti-mouse antibodies against fluorescein isothiocyanate (FITC)-conjugated CD34 (cat. no. 553733), phycoerythrin (PE)-conjugated KDR (cat. no. 555308), PE-conjugated CD45 (cat. no. 561087), and PE-conjugated CD146 (cat. no. 562196) were purchased from BD Biosciences (Franklin Lakes, NJ, USA). Anti-mouse FITC-conjugated antibodies against CD133 (cat. no. 85-11-1331-80) were purchased from eBioscience (San Diego, CA). Ulex europaeus agglutinin-1 (UEA-1) lectin was obtained from Vector Laboratories, Inc. (cat. no. B-1065-2; Burlingame, CA, USA) and the Transwell plate was purchased from Corning, Inc. (Corning, NY, USA). Bovine serum albumin was purchased from Beyotime Institute of Biotechnology (Nantong, China). Fetal bovine serum (FBS), TRIzol and DiI-acLDL were purchased from Thermo Fisher Scientific, Inc. (Waltham, MA, USA). The Masson's trichrome staining kit (cat. no. D026) and vascular endothelial growth factor A (VEGFA) Assay kit (cat. no. H044) were obtained from Nanjing Jiancheng Bioengineering Institute (Nanjing, China) to detect secreted VEGFA in the culture medium according manufacturer's protocol. The GTVisinTM anti-mouse/anti-rabbit immunohistochemical analysis kit was purchased from Gene Company, Ltd. (Hong Kong, China). Anti-phosphorylated (p)65 (cat. no. 8242), anti-phosphate-p65 (cat. no. 3033), anti-CD31 (cat. no. 3528), anti- $\alpha$-smooth muscle actin (SMA; cat. no. 19245), anti-GAPDH (cat. no. 5174), Alexa Fluor ${ }^{\circledR} 488$ conjugated anti-mouse immunoglobulin (Ig)G (cat. no. 4408), Alexa Fluor ${ }^{\circledR} 488$ conjugated anti-rabbit IgG (cat. no. 4412) and horseradish peroxidase conjugated goat anti-rabbit Immunoglobulin G (1:2,000; cat. no. 7074) antibodies, as well as RIPA Buffer (10X; cat. no. 9806) were purchased from Cell Signaling Technology, Inc. (Danvers, MA, USA). Fn14 small interfering (si)RNA (cat. no. sc-145209) and anti-VEGFA (1:500; cat. no. sc-4570) were purchased from Santa Cruz Biotechnology, Inc. (Dallas, TX, USA). Dimethylsulfoxide (DMSO), isopropanol, ethanol and chloroform were purchased from Sinopharm Chemical Reagent Co., Ltd. (Shanghai, China).

Patient information. Peripheral blood samples were collected from 25 male patients with AMI and 25 healthy male volunteers (age, 60-80 years) were recruited between January and June 2016. The patients were admitted to Zhongda Hospital
(Nanjing, China), diagnosed for the first time, and did not have a history of AMI, exhibited ST-segment elevation, serum CK-MB $>5 \mathrm{ng} / \mathrm{ml}$ and serum Troponin $\mathrm{T}>0.2 \mathrm{ng} / \mathrm{ml}$. The healthy volunteers were recruited to Zhongda Hospital, and exhibited normal ST-segments, serum CK-MB $<0.6 \mathrm{ng} / \mathrm{ml}$ and serum Troponin $\mathrm{T}<0.1 \mathrm{ng} / \mathrm{ml}$. The use of human samples was approved by the Ethics Committee of Zhongda Hospital, Medical School of Southeast University (Nanjing, China) and written informed consent was obtained from all patients prior to enrollment.

EPC isolation and identification. EPCs are derived from the bone marrow under pathological conditions and are associated with neovascularization and tissue repair (7). EPCs were derived from $\mathrm{C} 57 \mathrm{Bl} / 6$ mice as previously described $(15,16)$. A total of 160 10-12-week-old male C57Bl/6 mice (weight, 20-22 g) were obtained from the Laboratory Animal Center of Southeast University. The mice were housed in sterilized cages at $21 \pm 1^{\circ} \mathrm{C}$ with a $12 \mathrm{~h}$ light/dark cycle and $55 \pm 5 \%$ relative humidity, and received sterilized food and water ad libitum. Animal experiments were approved by The Animal Care Committee of the Southeast University. A total of $3 \mathrm{C} 57 \mathrm{Bl} / 6$ mice were sacrificed by cervical dislocation and soaked in $75 \%$ ethanol at room temperature for $10 \mathrm{~min}$. The tibiofibula was removed and the bone marrow was washed using $1 \mathrm{ml}$ PBS containing $50 \mathrm{U} / \mathrm{ml}$ heparin and $0.05 \mathrm{mg} / \mathrm{ml}$ DNase (both Sigma-Aldrich; Merck KGaA). The resulting fluid was collected, added to lymphocyte separation medium (Yeason, Shanghai, China) and centrifuged at a 3,000 x g for $30 \mathrm{~min}$ at room temperature. The white intermediate segment was then collected and washed using PBS. Collected cells were centrifuged at $500 \mathrm{x}$ g for $5 \mathrm{~min}$ at room temperature and resuspended with EBM-2 medium containing $100 \mathrm{U} / \mathrm{ml}$ penicillin, $100 \mathrm{U} / \mathrm{ml}$ streptomycin and $2 \%$ FBS.

Isolated EPCs were then cultured with EGM-2 and incubated in a humidified atmosphere containing $5 \% \mathrm{CO}_{2}$ at $37^{\circ} \mathrm{C}$. The medium was replaced every 3 days. On day 14, cells were digested with $0.04 \%$ collagenase type I (Sigma-Aldrich; Merck KGaA) and resuspended in PBS. Following an incubation with FcR blocking reagent (Miltenyi Biotec $\mathrm{GmbH}$, Bergisch Gladbach, Germany) on ice for $10 \mathrm{~min}$, cells were then stained for $30 \mathrm{~min}$ at $4^{\circ} \mathrm{C}$ with antibodies against CD34, KDR, CD45, CD133 and CD146 (all 1:200), then cells were washed three times with $0.01 \mathrm{M}$ PBS for 2 min each in the dark. To verify positive cells using BD FACSCalibur ${ }^{\mathrm{TM}}$ flow cytometer (BD Biosciences), the results were analyzed using FlowJo software (version 3.2; Treestar, Inc., Ashland, OR, USA).

Cell viability. EPCs were seeded into a 96-well culture plate at a density of $5 \times 10^{4}$ cells/well and treated with 0, 50, 100 and 150 ng/ml TWEAK (cat. no. ab184591; Abcam, Cambridge, MA, USA) for $24 \mathrm{~h}$ at $37^{\circ} \mathrm{C}$ in incubator. Prior to TWEAK treatment, EPCs were either transfected with 2 pmol Fn14 siRNA or 2 pmol scramble siRNA using Lipofectamine ${ }^{\circledR}$ RNAiMAX reagent (Invitrogen; Thermo Fisher Scientific, Inc.) according to the manufacturer's protocol for 3 days, and treated with $5 \mu \mathrm{M}$ Bay 11-7082 (cat. no. S2913; Selleck Chemicals, Shanghai, China) for $1 \mathrm{~h}$ at $37^{\circ} \mathrm{C}$ or left untreated. MTT ( $1 \mathrm{mg} / \mathrm{ml}$, dissolved in PBS solution; $100 \mu \mathrm{l} / \mathrm{well}$; 
Sigma-Aldrich; Merck KGaA) was then added for $4 \mathrm{~h}$ at $37^{\circ} \mathrm{C}$, followed by the addition of $100 \mu \mathrm{l}$ DMSO. The absorbance was determined using a multiplate reader at a wavelength of $570 \mathrm{~nm}$.

AMI mouse model. The AMI murine model was prepared as previously described (17). Mice were anesthetized using intraperitoneal injection of $300 \mathrm{mg} / \mathrm{kg}$ chloral hydrate (18), which was approved by the Ethics Committee of Zhongda Hospital, Medical School of Southeast University and the loss of righting reflex was monitored to ensure that the all mice were fully anesthetized in the experiments. Mice were artificially ventilated using a volume-regulated respirator. Hearts were exposed via left thoracotomy and the left coronary artery was ligated between the pulmonary artery conus and the left atrium using an 8-0 prolene suture. Following 30 min, 74 surviving mice were randomly divided into four groups [AMI, EPCs treatment $\left(1 \times 10^{6}\right.$ cells in $30 \mu \mathrm{l}$ PBS), TWEAK pretreated EPCs and sham; n=8/group] or six groups (AMI, EPC treatment, TWEAK pretreated EPC group, TWEAK pretreated Fn14 siRNA EPC, TWEAK pretreated Bay 11-7082 EPC and sham; n=10/group). Mice in the sham group underwent thoracotomy but not ligation. A total of 30 healthy mice and 30 AMI mice were sacrificed to detect the content of TWEAK in serum. EPCs $\left(1 \times 10^{6} / 30 \mu \mathrm{l}\right)$ labeled with DiD dye (cat. no. V22887; 1:1,000; Invitrogen; Thermo Fisher Scientific, Inc.) for $1 \mathrm{~h}$ at room temperature and washed with 0.01 M PBS two times. The cells were intramyocardially injected into mice to assess the adherence of EPCs to injured heart tissue. At $30 \mathrm{~min}$ following coronary ligation, $1 \times 10^{6}$ cells $/ 30 \mu 1$ in PBS or PBS alone were administered into the myocardium.

Echocardiography. Transthoracic two-dimensional M mode echocardiograms and pulsed wave Doppler spectral tracings were produced using a Toshiba Aplio 80 Imaging System (Toshiba Medical Systems Corporation, Tochigi, Japan) equipped with a $12 \mathrm{MHz}$ linear transducer. Echocardiographic studies were performed on mice with a maintained body temperature of $37^{\circ} \mathrm{C}$. M-mode tracings were used to measure left ventricle (LV) wall thickness, end-systolic dimensions (ESD) and end-diastolic dimensions (EDD).

Tube formation assay. A 24-well culture plate was placed on ice and $0.289 \mathrm{ml} /$ well chilled Matrigel Matrix $(10 \mathrm{mg} / \mathrm{ml}$; BD Biosciences) was added. The plate was then incubated at $37^{\circ} \mathrm{C}$ for $30 \mathrm{~min}$ and the remaining matrix was removed. A total of $300 \mu \mathrm{l}$ cell suspension $\left(1 \times 10^{5}\right.$ cells) was added to each well and incubated at $37^{\circ} \mathrm{C}$ for $24 \mathrm{~h}$.

Transwell assay. EGM-2 medium containing 10\% FBS $(0.6 \mathrm{ml})$ was added to the lower compartment of a Transwell plate with an $8 \mu \mathrm{m}$ pore insert. A total of $5 \times 10^{4}$ cells in EGM-2 serum free medium were added to the upper compartment and incubated at $37^{\circ} \mathrm{C}$ for $12 \mathrm{~h}$. Cells in the lower chamber were fixed with $4 \%$ paraformaldehyde at room temperature for $10 \mathrm{~min}$ and stained with $1 \%$ crystal violet in $2 \%$ ethanol at room temperature for $20 \mathrm{~min}$. The number of cells in the lower chamber were counted under a light microscope (magnification, $\mathrm{x} 20$ ).
Histology. A histological examination was performed on three samples of mouse heart from the same position under a light microscope (magnification, x20). Samples were fixed with $10 \%$ formalin at room temperature overnight, embedded in paraffin and sliced into $4 \mu \mathrm{m}$ thick sections. Slides were processed using a GTVisinTM anti-mouse/anti-rabbit immunohistochemical analysis kit according to the manufacturer's protocol.

Masson's trichrome staining. Masson's trichrome staining for 20 min was performed at room temperature using the aforementioned kit to distinguish collagen fibers from muscular tissues. Blue staining indicated a positive result. Staining was performed according to the manufacturer's protocol.

Western blotting. EPCs were collected following various treatments. Whole protein was extracted from whole cell lysate using RIPA buffer and the concentration was measured using a BCA assay. The protein $(20 \mu \mathrm{g})$ was separated by $12.5 \%$ SDS-PAGE. Proteins were transferred to polyvinylidene membranes (EMD Millipore, Billerica, MA, USA) at $300 \mathrm{~mA}$ for $90 \mathrm{~min}$. The membranes were then blocked at room temperature for $1 \mathrm{~h}$ with TBST containing $0.1 \%$ Tween-20 and 5\% dry milk and incubated overnight with primary antibodies against p65, phospho-p65, CD31, $\alpha$-SMA (all 1:1,000) and GAPDH $(1: 2,000)$ at $4^{\circ} \mathrm{C}$. Membranes were washed in triplicate with TBST and incubated for $2 \mathrm{~h}$ with horseradish peroxidase-conjugated goat anti-rabbit antibody $(1: 2,000)$ at room temperature. The optical densities of antibody-specific bands were analyzed using a Luminescent Image Analyzer (Protein Simple, San Jose, CA, USA) and ImageJ software (version 1.37 for Windows; National Institutes of Health, Bethesda, MD, USA).

Immunofluorescence. Cells $\left(5 \times 10^{4} / \mathrm{ml}\right)$ cultured with $2 \mu \mathrm{g} / \mathrm{ml}$ UEA-1 Lectin and $5 \mu \mathrm{g} / \mathrm{ml}$ Dil-acLDL at room temperature for $30 \mathrm{~min}$, washed three times with PBS and fixed with $4 \%$ paraformaldehyde for $30 \mathrm{~min}$. The cells were observed using a confocal microscope (magnification, $\mathrm{x} 40$ ) to verify that they were EPCs. DiD-labelled EPCs $\left(1 \times 10^{6}\right)$ were injected into AMI mice. After 14 days, the mice were sacrificed by cervical dislocation. Then, heart slices were fixed with $4 \%$ paraformaldehyde at room temperature overnight, permeabilized with $0.3 \%$ Triton X-100 for $30 \mathrm{~min}$ at room temperature and sliced into $4-\mu \mathrm{m}$-thick sections. Following blocking with $3 \%$ bovine serum albumin for $1 \mathrm{~h}$ at room temperature, the sections were incubated with antibodies against CD31 and $\alpha$-SMA $(1: 1,000)$ at room temperature for $2 \mathrm{~h}$. Slides were washed three times with PBS and incubated with Alexa Fluor 488-conjugated secondary antibodies $(1: 1,000)$ for $1 \mathrm{~h}$ at room temperature. Nuclei were stained with DAPI $(10 \mu \mathrm{g} / \mathrm{ml})$ for $5 \mathrm{~min}$ at room temperature. Images were acquired using confocal microscopy (magnification, $\mathrm{x} 40$ ).

Reverse-transcription quantitative polymerase chain reaction (RT-qPCR) analysis. RNA was removed from TWEAK-treated EPCs using $1 \mathrm{ml}$ of TRIzol and the cDNA was generated using PrimeScript ${ }^{\mathrm{TM}}$ RT Master Mix (Takara, Kyoto, Japan) for $15 \mathrm{~min}$ at $37^{\circ} \mathrm{C}$. The reaction was terminated by heating the samples at $85^{\circ} \mathrm{C}$ for $5 \mathrm{sec}$. The specific primers of VEGFA 
(sense 5'-AAAGGCTTCAGTGTGGTCTGAGAG-3' and antisense 5'-GGTTGGAACCGGCATCTTTATC-3') and GAPDH (sense 5'-CGACTTCAACAGCAACTCCCACTCTTCC-3' and antisense 5'-TGGGTGGTCCAGGGTTTCTTACTC CTT-3'; both Shenggong, Shanghai, China) were mixed with $100 \mathrm{ng}$ cDNA and qPCR was performed using the DyNAmo SYBR Green 2-step RT-qPCR kit (cat. no. F430L; Finnzymes; Thermo Fisher Scientific, Inc.). The experimental protocol was as follows: $95^{\circ} \mathrm{C}$ for $10 \mathrm{~min}$ (denaturation), 35 cycles of $95^{\circ} \mathrm{C}$ for $15 \mathrm{sec}, 60^{\circ} \mathrm{C}$ for $10 \mathrm{sec}, 72^{\circ} \mathrm{C}$ for $45 \mathrm{sec}$ (amplification and quantification program), a melting curve program consisting of $15 \mathrm{sec}$ at $95^{\circ} \mathrm{C}$ (denaturation), $30 \mathrm{sec}$ at $55^{\circ} \mathrm{C}$ (annealing) and a melting and continuous measuring step at $0.5^{\circ} \mathrm{C} / \mathrm{sec}$ up to $85^{\circ} \mathrm{C}$, and finally a cooling step at $40^{\circ} \mathrm{C}$. Data collection was performed using the ABI PRISM 7000 Sequence Detection System (Applied Biosystems; Thermo Fisher Scientific, Inc.). GAPDH was used as an internal control. The $2^{-\Delta \Delta C q}$ method was applied to analyze the relative changes in VEGFA gene expression (19).

Statistical analysis. Experimental data are expressed as the mean \pm standard deviation of at least three independent experiments. Statistical analyses were performed using unpaired Student's t-test or one-way analysis of variance followed by Tukey's test, and SPSS 18.0 statistical software (SPSS, Inc., Chicago, IL, USA). $\mathrm{P}<0.05$ was used to indicate a statistically significant difference.

\section{Results}

TWEAK expression in patients and mice with AMI. It has been demonstrated that TWEAK is upregulated in tissue injury (20). A retrospective analysis was performed on blood samples obtained from 25 patients with AMI and 25 healthy volunteers, as well as mice with experimentally induced AMI. As presented in Fig. 1A and B, TWEAK was significantly upregulated in patients and mice with AMI compared with their respective healthy controls.

Characterization of cultured EPCs. Murine EPCs derived from the bone marrow were collected using lymphocyte separation medium. EPCs were verified using UEA-1 Lectin (early EPCs marker) and Dil-acLDL (late EPCs marker) double staining, as presented in Fig. 2A. EPCs were further verified using flow cytometry. It was demonstrated that EPCs express CD34, KDR and CD146, but not CD45 and CD133 (Fig. 2B). In order to identify the function of EPCs in AMI, DiD-stained EPCs were injected into mice with AMI. The results revealed that EPCs can migrate to damaged tissues, and differentiate into veins (indicated by CD31 expression) and arteries (indicated by $\alpha$-SMA expression; Fig. 2C).

EPCs pre-incubated with TWEAK improve cardiac function, alleviate AMI and promote vasculogenesis in murine hearts. EPCs were preincubated with $100 \mathrm{ng} / \mathrm{ml}$ TWEAK for $24 \mathrm{~h}$ and injected into the myocardium of mice with AMI to assess whether TWEAK affects EPCs in AMI. M-mode images indicated that the LV cavity was dilated in AMI, however this effect was markedly reduced by treatment with TWEAK-treated EPCs compared with untreated EPCs
A
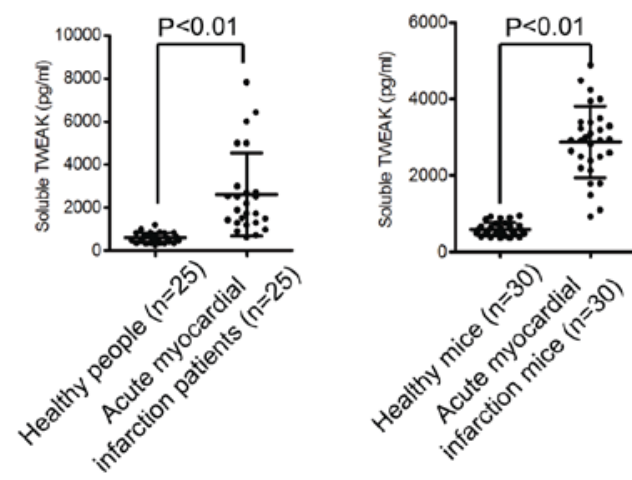

Figure 1. Patients with AMI exhibit a high concentration of TWEAK. Soluble TWEAK contents in the serum of patients and mice with acute myocardial infarction were significantly increased. (A) Patients with AMI exhibited significantly higher levels of TWEAK on admission compared with healthy participants ( $\mathrm{n}=25 /$ group; $\mathrm{P}<0.01)$. (B) TWEAK levels in mice with AMI $(n=30)$ were also significantly higher compared with those of healthy mice $(\mathrm{n}=30$ /group; $\mathrm{P}<0.01)$. The data was assessed using Student's t-test. AMI, acute myocardial infarction; TWEAK, tumor necrosis factor-related weak inducer of apoptosis.

(Fig. 3A). The effect of EPCs pre-treated with TWEAK on various physiological parameters and cardiac functions in AMI mice are presented in Table I. In contrast to AMI mice, EPC treatment decreased heart weight/body weight, left ventricular internal diameter at end-diastole, left ventricular internal diameter at end-systole (LVIDs), and increased left ventricular ejection fraction (LVEF) and left ventricular fractional shortening (LVFS) in AMI mice. Compared with the EPC+AMI group, EPCs pre-treated with TWEAK were demonstrated to further increase LVEF and LVFS, while LVIDs was reduced. Masson's trichrome staining revealed that EPCs pre-treated with TWEAK downregulated collagen synthesis and infarct size in the AMI and EPC+AMI groups (Fig. 3B and C). Although EPC treatment appears to exacerbate the effect of AMI, the infarction decreased. Capillary density in the infarct area was assessed using immunohistochemical staining. A marked increase in angiogenesis was observed in untreated and TWEAK-treated EPC groups as CD31 staining increased; however, the degree of angiogenesis was greatest in TWEAK pre-treated EPCs compared with the AMI and EPC+AMI groups. Previous studies have indicated that EPCs may contribute to arteriogenesis $(21,22)$. The expression of a-SMA was used as a measure of arteriogenesis. The results demonstrated that arteriogenesis was greatest in EPCs pre-treated with TWEAK (Fig. 3D). The results indicate that TWEAK treatment improves cardiac function, decreases collagen synthesis and facilitates EPC differentiation in AMI.

TWEAK promotes migration, tube formation, viability and VEGFA generation in EPCs. The effect of TWEAK treatment on EPC migration, tube formation and cell viability was assessed in vitro. Migrating cells were stained with crystal violet and counted using a light microscope. As presented in Fig. 4A, the migration of EPCs was dependent on the concentration of TWEAK. It was also demonstrated that TWEAK promotes tube formation in a dose-dependent manner (Fig. 4B). 
A

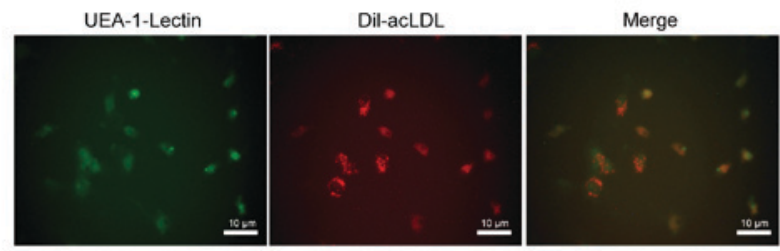

B
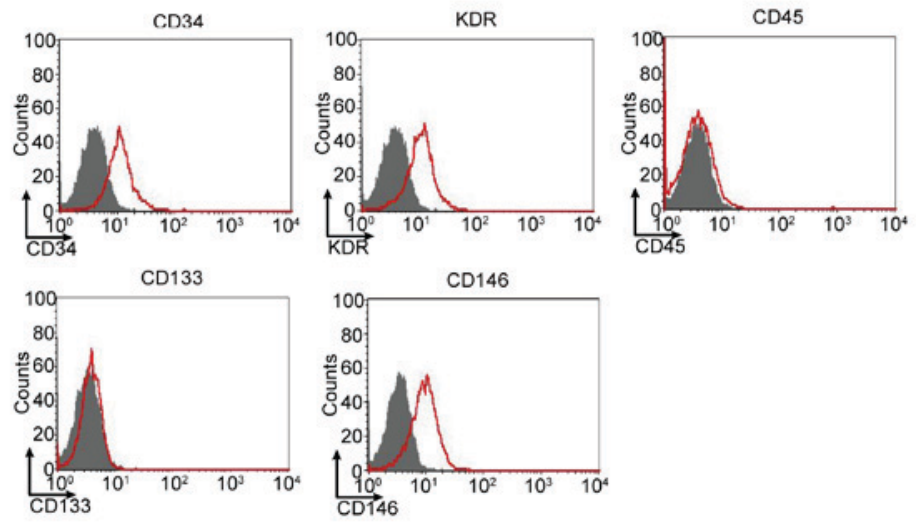

C

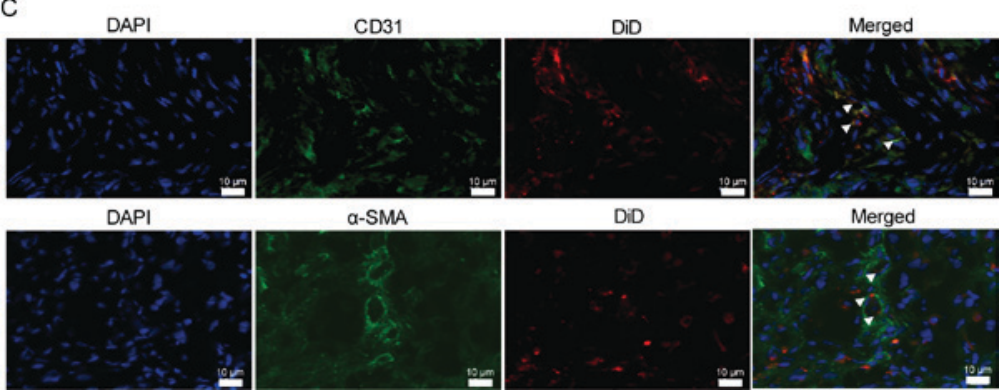

Figure 2. Phenotypic characterization of cultured EPCs. EPCs exhibited a change toward mesenchymal transformation following transplantation in AMI mice. (A) UEA-1 lectin binding (green) and DiI-acLDL molecular probe uptake (red) were evaluated in early and late EPCs to confirm culture using photomicrographs. (B) EPCs expressed CD34, KDR and CD146, but were negative for CD45 and CD133, as assessed using flow cytometry. (C) Immunofluorescent staining was performed with antibodies against CD31 and $\alpha$-SMA to detect the differentiation of EPCs labeled with DiD in veins and arteries following transplantation in AMI mice. White triangles indicate the differentiated EPCs. EPCs, EPC, endothelial progenitor cells; AMI, acute myocardial infarction; UEA-1, ulex europaeus agglutinin-1; CD, cluster of differentiation; KDR, kinase domain receptor; SMA, smooth muscle actin.

Next, cell viability was assessed using an MTT assay. It was demonstrated that TWEAK treatment increased the viability of EPCs in a dose-dependent manner (Fig. 4C). To further assess vasculogenesis and tube formation, levels of VEGFA mRNA and released VEGFA in the medium were detected following TWEAK treatment. TWEAK was demonstrated to promote VEGFA expression and increase the release of VEGFA into the medium in a dose-dependent manner (Fig. 4D).

TWEAK promotes EPC migration, tube formation and viability via the Fn14-NF- $\kappa$ B pathway. Fn14 siRNA and Bay 11-7082, an inhibitor of the NF- $\mathrm{B}$ pathway, were used to determine whether Fn14-NF- $\kappa \mathrm{B}$ signaling is associated with the mechanism of TWEAK-mediated EPC-induced cardiac protection. As presented in Fig. 5A, Fn14-siRNA and Bay 11-7082-treated EPCs that received $100 \mathrm{ng} / \mathrm{ml}$ TWEAK for $24 \mathrm{~h}$ exhibited decreased migration and tube formation when compared with TWEAK-treated EPCs group (Fig. 5B). However, compared with scramble EPCs, Fn14 siRNA or Bay 11-7082-treated EPCs in the absence of TWEAK demonstrated no marked difference in migration or tube formation. Furthermore, the results demonstrated that TWEAK-mediated EPC viability is inhibited by Fn14 depletion or NF- $\mathrm{BB}$ inhibition (Fig. 5C).
TWEAK treatment alone also upregulated activated p65 and downstream VEGFA; however, further Fn14-siRNA or Bay 11-7082 treatment significantly decreased the expression of phosphorylated p65 and VEGFA (Fig. 5D-F). The results indicated that the TWEAK-Fn14-NF- $\kappa$ B pathway serves a role in EPC migration, vasculogenesis and viability.

EPCs pretreated with TWEAKalleviate AMI via the Fn14-NF- $\mathrm{BB}$ pathway. To further ascertain whether the protective effect of TWEAK on EPC transplantation is mediated by the Fn14 and NF- $\kappa$ B pathway, EPCs were treated with Fn14-siRNA and Bay 11-7028, followed by TWEAK. M-mode images revealed that the anterior and posterior walls of the heart were thinner in mice with AMI compared with normal mice (Fig. 6A). Furthermore, the LVEF and LVFS were significantly reduced following the induction of MI (Fig. 6A). EPCs pretreated with TWEAK for $24 \mathrm{~h}$ prior to transplantation were demonstrated to protect cardiac function in mice with AMI via the Fn14-NF- $\kappa$ B pathway. Fn14-siRNA and Bay 11-7028 treatment increased the ESD and EDD, while the LVEF and LVFS were decreased (Fig. 6A). Inhibiting Fn14 or NF- $\mathrm{NB}$ signaling alleviated the protective effect of TWEAK on a number of physiological parameters and cardiac functions (Table II). Furthermore, Masson's trichrome 
A

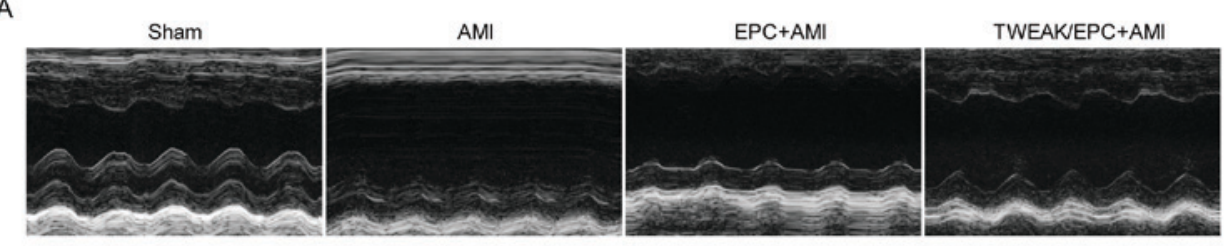

B
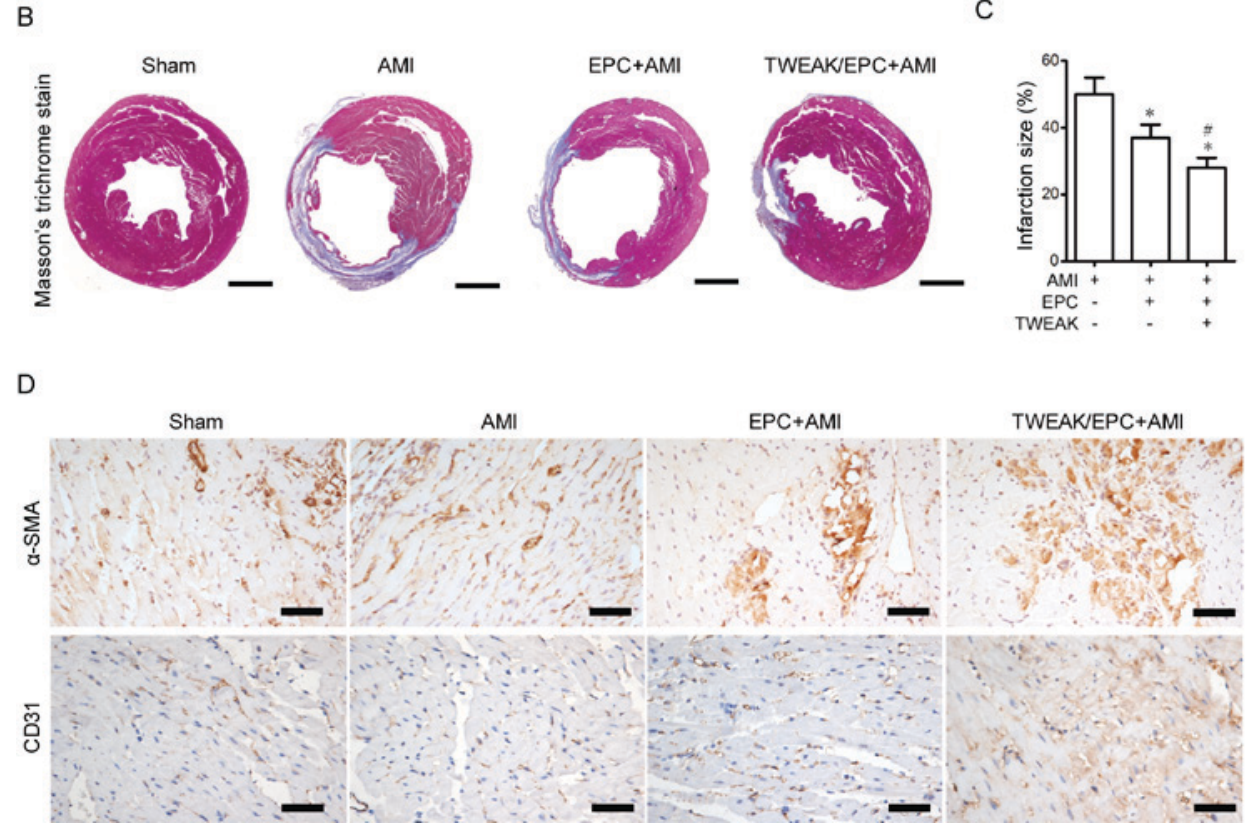

Figure 3. EPCs pre-incubated with TWEAK alleviated AMI and promoted vasculogenesis in murine hearts. (A) Echocardiographic images of murine hearts transplanted with TWEAK pretreated EPCs following the induction of myocardial infarction. (B) Masson's trichrome staining (blue) demonstrated that TWEAK + EPC treatment downregulated collagen fibers in the hearts of mice with AMI (scale bar $=0.2 \mathrm{~cm})$. (C) Transplantation of TWEAK pretreated EPCs reduced the size of myocardial infarction. $\mathrm{n}=5,{ }^{*} \mathrm{P}<0.05$ vs. the AMI mice, ${ }^{\sharp} \mathrm{P}<0.05$ vs. the EPC+AMI group. (D) TWEAK treated EPCs promoted angiogenesis (indicated by $\alpha$-SMA) and arteriogenesis (indicated by CD31) in mice with AMI (scale bar=50 $\mu \mathrm{m}$ ). EPCs, EPC, endothelial progenitor cells; TWEAK, tumor necrosis factor-related weak inducer of apoptosis; AMI, acute myocardial infarction; SMA, smooth muscle actin; CD, cluster of differentiation.

staining was enhanced in Fn14-siRNA and Bay 11-7028-treated EPCs of AMI mice compared with TWEAK-pretreated EPCs of AMI mice (Fig. 6B). AMI was assessed via the histological examination of infarct size and it was demonstrated that Fn14 or $\mathrm{NF}-\kappa \mathrm{B}$ inhibition significantly alleviated the protective effect of TWEAK-pretreated EPCs (Fig. 6C). Fn14 depletion or NF- $\kappa \mathrm{B}$ pathway inhibition in TWEAK-pretreated EPCs slightly decreased the expression of $\alpha$-SMA-positive (Fig. 6D) and CD31-positive (Fig. 6E) microvessels in vivo compared with TWEAK-pretreated EPCs. As such, the TWEAK mediated $\mathrm{NF}-\kappa \mathrm{B}$ pathway in EPCs has a protective effect in mice with AMI.

\section{Discussion}

EPC transplantation may be a promising strategy for the treatment of patients with AMI. It has been reported that EPCs bind to UEA-1 and uptake acetylate low-density lipoprotein in vivo after 4-7 days (23). A number of hematopoietic cells have exhibited similar capabilities (15). In the present study, the expression of CD34, KDR, CD45, CD133 and CD146 was used to assess EPCs. The results demonstrated that cultured EPCs migrate to injured tissues and differentiate into blood vessels in vivo. However, there are many additional factors that promote EPC activation and differentiation, including cytokines, hypoxia, exercise and Olmesartan $(24,25)$.
VEGFA promotes vessel formation, while VEGFA and stromal cell-derived factor (SDF-)1 released from injured vascular tissues bind to the VEGF receptor $(\mathrm{R})$ and $\mathrm{C}-\mathrm{X}-\mathrm{C}$ motif chemokine receptor 4 (CXCR4) to recruit more EPCs (26). SDF-1 binds to CXCR4, activating phosphoinositide 3-kinase $(\mathrm{PI} 3 \mathrm{~K})$ and promoting the generation and release of nitrous oxide (NO) via the Akt-mediated phosphorylation of endothelial nitrous oxide synthase (eNOS) (27). VEGFA also promotes eNOS phosphorylation, followed by NO production to promote EPC growth and migration $(28,29)$. When EPCs migrate to injured tissues, adhesion molecules including P-selectin, E-selectin and intracellular adhesion molecule 1 expressed on endothelial cells bind to P-selectin glycoprotein ligand 1 and $\beta 2$ integrins expressed on EPCs to promote movement across the endothelium into the stroma $(30,31)$. In addition to VEGFR and CXCR4, other factors and signaling pathways may be associated with the promotion of EPC growth and migration.

TWEAK is a proinflammatory factor that is released under pathological conditions and is upregulated in patients with AMI (5). It was upregulated in AMI patients. In order to assess the effect of TWEAK, EPCs were treated with $100 \mathrm{ng} / \mathrm{ml}$ soluble TWEAK and transplanted into AMI mice. The results demonstrated that EPC transplantation repairs injured myocardial tissue, significantly improves cardiac function and promotes the differentiation of EPCs to form vessels. 
Table I. Effect of TWEAK-treated EPCs on physiological parameters and cardiac functions at 14 days following AMI induction.

\begin{tabular}{|c|c|c|c|c|}
\hline \multirow[b]{2}{*}{ Variable } & \multicolumn{4}{|c|}{ Group } \\
\hline & Sham & AMI & $\mathrm{EPC}+\mathrm{AMI}$ & TWEAK/EPC+AMI \\
\hline HW/BW (mg/g) & $5.43 \pm 0.21$ & $8.12 \pm 0.33^{\mathrm{a}}$ & $7.12 \pm 0.36^{\mathrm{c}}$ & $6.62 \pm 0.46^{c}$ \\
\hline LVEF (\%) & $80.37 \pm 0.54$ & $27.32 \pm 0.23^{\mathrm{b}}$ & $35.48 \pm 1.54^{\mathrm{c}}$ & $65.73 \pm 0.52^{\mathrm{d}, \mathrm{e}}$ \\
\hline LVFS (\%) & $50.32 \pm 0.82$ & $13.15 \pm 0.95^{\mathrm{b}}$ & $18.19 \pm 0.71^{\mathrm{c}}$ & $25.33 \pm 0.22^{c, e}$ \\
\hline LVIDd (mm) & $3.17 \pm 0.60$ & $6.17 \pm 0.26^{\mathrm{a}}$ & $5.21 \pm 0.32^{\mathrm{c}}$ & $4.12 \pm 0.51^{\mathrm{c}}$ \\
\hline LVIDs (mm) & $1.55 \pm 0.18$ & $4.65 \pm 0.27^{\mathrm{a}}$ & $3.38 \pm 0.25^{\mathrm{c}}$ & $2.60 \pm 0.25^{\mathrm{c}, \mathrm{e}}$ \\
\hline
\end{tabular}

Values are expressed as the mean \pm standard error of the mean ( $\mathrm{n}=6$ for each group). ${ }^{\mathrm{a}} \mathrm{P}<0.05$ and ${ }^{\mathrm{b}} \mathrm{P}<0.01$ vs. the sham group. ${ }^{\mathrm{c}} \mathrm{P}<0.05$ and ${ }^{\mathrm{d}} \mathrm{P}<0.01$ vs. the AMI group. ${ }^{\mathrm{e}} \mathrm{P}<0.05$ vs. the EPC group. TWEAK, tumor necrosis factor-related weak inducer of apoptosis; EPC, endothelial progenitor cell; AMI, acute myocardial infarction; HW, heart weight; BW, body weight; LVEF, left ventricular ejection fraction; LVFS, left ventricular fractional shortening; LVIDd, left ventricular internal diameter at end-diastole; LVIDs, left ventricular internal diameter at end-systole.

A
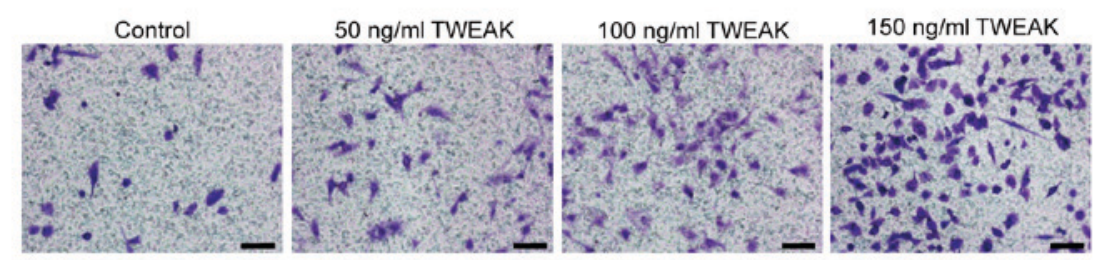

B

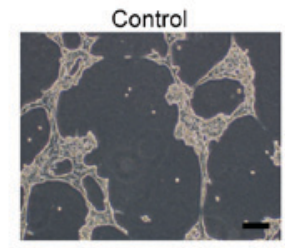

$50 \mathrm{ng} / \mathrm{ml}$ TWEAK

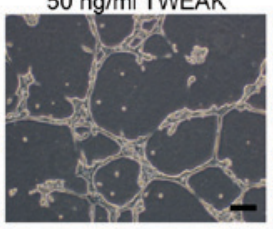

$100 \mathrm{ng} / \mathrm{ml}$ TWEAK

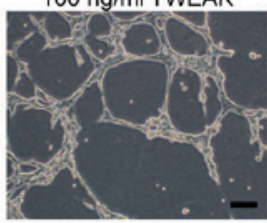

$150 \mathrm{ng} / \mathrm{ml}$ TWEAK

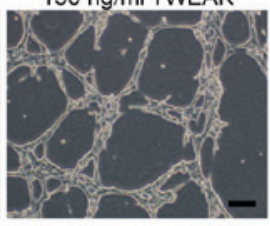

C

D
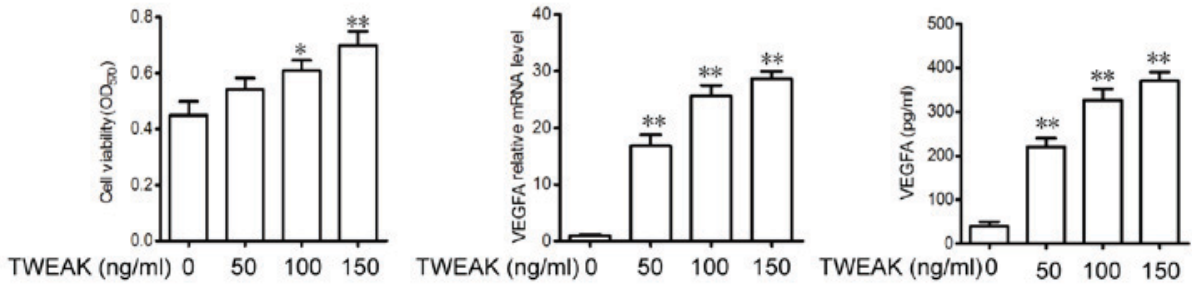

Figure 4. TWEAK promotes EPC migration, tube formation and viability, as well as the generation of VEGFA in EPCs. (A) EPCs were treated with 50, 100 and $150 \mathrm{ng} / \mathrm{ml}$ TWEAK and seeded (5x104/well) into Transwell plates for $12 \mathrm{~h}$ to assess migration (scale bar, $50 \mu \mathrm{m}$ ). (B) A tube formation assay was performed (scale bar, $100 \mu \mathrm{m}$ ). (C) The viability of EPCs treated with 50,100 and $150 \mathrm{ng} / \mathrm{ml}$ TWEAK was measured via an MTT assay. (D) VEGFA mRNA levels and the concentration of VEGFA secreted into medium following TWEAK treatment were measured using reverse-transcription quantitative polymerase chain reaction and ELISA, respectively. ${ }^{*} \mathrm{P}<0.05$ and ${ }^{* *} \mathrm{P}<0.01 \mathrm{vs}$. the control $(0 \mathrm{ng} / \mathrm{ml}$ TWEAK) group. TWEAK, tumor necrosis factor-related weak inducer of apoptosis; EPCs, EPC, endothelial progenitor cells; VEGFA, vascular endothelial growth factor A.

TWEAK binds to Fn14 and initiates downstream signaling via the TNF receptor-associated factor (32). TWEAK/Fn14 promotes the nuclear translocation of $\mathrm{NF}-\kappa \mathrm{B}$ and increases the downstream expression of genes, including regulated upon activation normal $\mathrm{T}$ cell expressed and secreted (RANTES) and monocyte chemoattractant protein-1 $(33,34)$. Furthermore, TWEAK/FN14 signaling-mediated $\mathrm{NF}-\kappa \mathrm{B}$ pathway activation contributes to the metastasis of prostate cancer (34). However, it has been reported that TWEAK aggravates ventricular damage following AMI by directly inhibiting oxidative phosphorylation of peroxisome proliferator-activated receptor- $\gamma$ coactivator $1 \alpha$ and cardiomyocytes (35). TWEAK treatment has also been demonstrated to accelerate collagen synthesis and heart fibroblast proliferation via NF- $\kappa$ B activation (36). In renal tubule epithelial cells, TWEAK activates extracellular signal related kinase (ERK), PI3K and NF- $\kappa \mathrm{B}$ signaling to accelerate their proliferation (37). Furthermore, ERK and PI3K inhibitors block the proliferation of renal tubular epithelial and myocardial cells (37). Inhibiting $\mathrm{NF}-\kappa \mathrm{B}$ signaling also prevents TWEAK-induced proliferation of renal tubular epithelial cells (37). NF- $\kappa \mathrm{B}$ signaling 
A

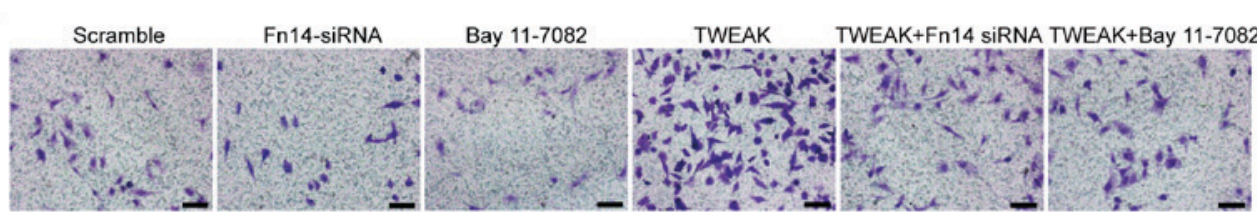

B

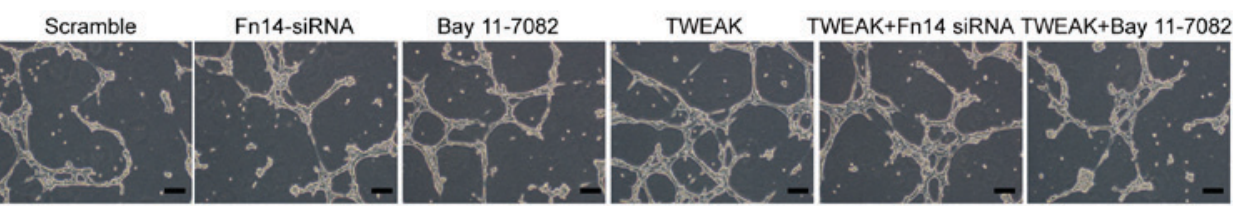

C

D
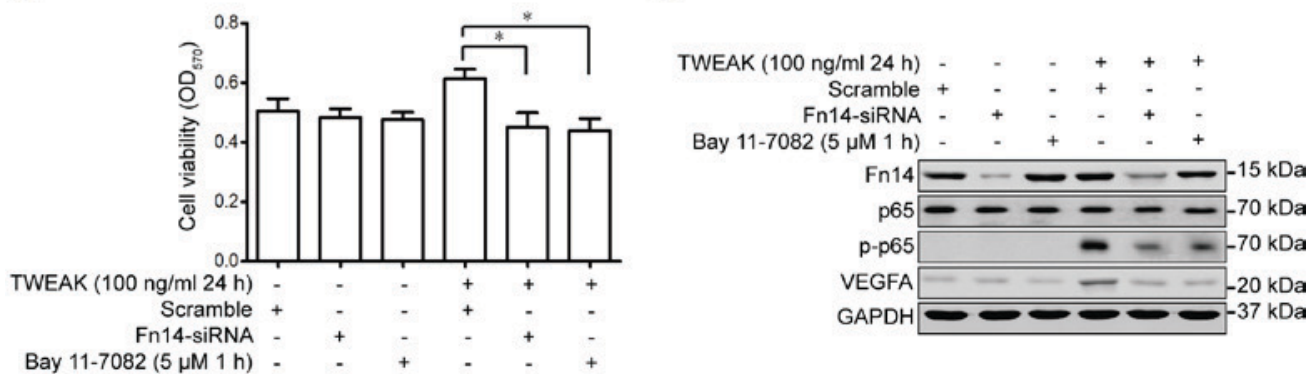

E
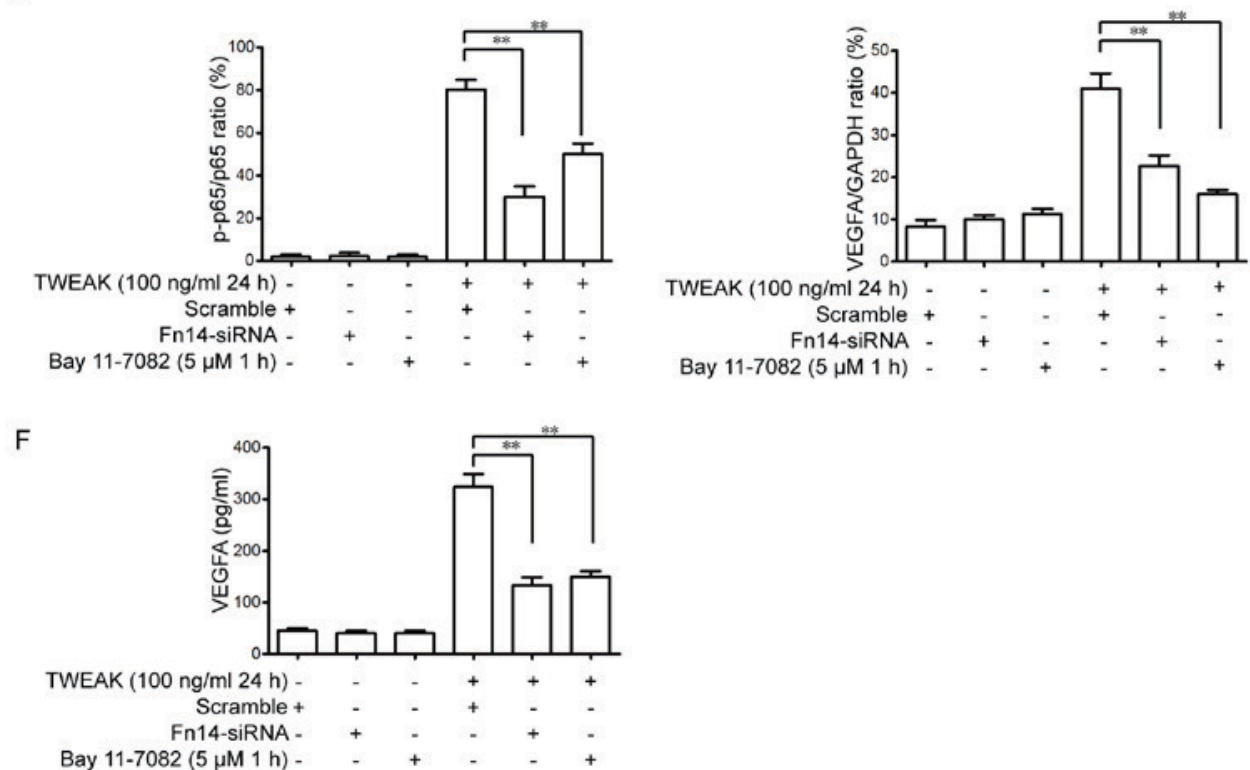

Figure 5. TWEAK promotes EPC migration, tube formation and viability via the Fn14-NF-kB pathway. EPCs were pre-treated with Fn14-siRNA or Bay 11-7028 for 48 or $1 \mathrm{~h}$, respectively. (A) EPCs then received $100 \mathrm{ng} / \mathrm{ml}$ TWEAK treatment for $24 \mathrm{~h}$ and were seeded (5x10 cells/well) into Transwell plates for $12 \mathrm{~h}$ (scale bar, $50 \mu \mathrm{m}$ ). (B) A tube formation assay was performed (scale bar, $100 \mu \mathrm{m}$ ). (C) The viability of EPCs were detected using an MTT assay. (D) The expression of Fn14, p65, p-p65 and VEGFA were measured using western blotting. (E) Quantitative analysis of p-p65 and VEGFA was calculated from three independent experiments. (F) Secreted VEGFA in the medium were assessed using ELISA. ${ }^{*} \mathrm{P}<0.05$ and ${ }^{* *} \mathrm{P}<0.01$ vs. the TWEAK+scramble group. TWEAK, tumor necrosis factor-related weak inducer of apoptosis; EPCs, EPC, endothelial progenitor cells; siRNA, small interfering RNA; Fn14, fibroblast growth factor-inducible 14; p, phosphorylated; VEGFA, vascular endothelial growth factor A.

is also critical for EPCs. It has been demonstrated that TGF- $\beta$-induced protein increases levels of notch ligands, including Jagged-1 and delta-like protein 1, to facilitate EPC differentiation and angiogenesis through activated $N F-\kappa B$ signaling (38). NF- $\kappa B$ inhibition has been demonstrated to decrease human endothelial cell growth and survival, as well as inhibiting the migration of gastric cancer cells $(39,40)$. In addition, VEGFA generation is regulated by $\mathrm{NF}-\kappa \mathrm{B}$ signaling to promote angiogenesis (41).

Given that Fn14 and NF- $\mathrm{B}$ signaling serve roles in EPCs, Fn14-siRNA and Bay 11-7028 were used to assess whether TWEAK facilitates the viability and differentiation of EPC via these pathways to alleviate AMI in mice. The results revealed that inhibiting Fn14 and NF- $\kappa$ B signaling downregulates the migration and tube formation of TWEAK pretreated EPCs in vitro. Additionally, it was demonstrated that downregulating the Fn14 or NF- $\kappa$ B pathways in TWEAK-pretreated EPCs promotes heart failure and increase infarct size in vivo, therefore decreasing the protective effect of EPCs. Downregulation of these pathways also decreased the expression of $\alpha$-SMA and CD31. However, whether other signaling pathways serve a role in 
Table II. Role of Fn14 or NF-кB signaling in TWEAK and its effect on physiological parameters and cardiac function, 14 days following AMI induction.

\begin{tabular}{|c|c|c|c|c|c|c|}
\hline Variable & Sham & AMI & $\mathrm{EPC}+\mathrm{AMI}$ & TWEAK/EPC+AMI & $\begin{array}{c}\text { TWEAK/Fn14 } \\
\text { siRNA EPC+AMI }\end{array}$ & $\begin{array}{c}\text { TWEAK/Bay } \\
\text { 11-7082/EPC+AMI }\end{array}$ \\
\hline HW/BW (mg/g) & $5.37 \pm 0.73$ & $7.64 \pm 0.73$ & $6.81 \pm 0.38$ & $6.21 \pm 0.84$ & $6.93 \pm 0.78$ & $7.14 \pm 0.64$ \\
\hline LVEF (\%) & $79.32 \pm 0.42$ & $31.02 \pm 0.38$ & $40.21 \pm 0.91$ & $65.33 \pm 0.84$ & $43.21 \pm 0.43^{\mathrm{a}}$ & $44.29 \pm 0.91^{\mathrm{a}}$ \\
\hline LVFS (\%) & $48.13 \pm 0.42$ & $12.25 \pm 0.55$ & $21.27 \pm 0.37$ & $31.48 \pm 0.42$ & $20.28 \pm 0.78^{\mathrm{a}}$ & $19.32 \pm 0.58^{\mathrm{a}}$ \\
\hline LVIDd (mm) & $3.28 \pm 0.43$ & $6.86 \pm 0.32$ & $5.13 \pm 0.57$ & $4.01 \pm 0.32$ & $5.23 \pm 0.89$ & $5.31 \pm 0.38^{\mathrm{a}}$ \\
\hline LVIDs (mm) & $1.41 \pm 0.17$ & $5.27 \pm 0.38$ & $4.01 \pm 0.46$ & $2.51 \pm 0.47$ & $4.32 \pm 0.78^{\mathrm{a}}$ & $4.21 \pm 0.58^{\mathrm{a}}$ \\
\hline
\end{tabular}

Values are expressed as the mean \pm standard error of the mean ( $\mathrm{n}=6$ for each group). ${ }^{\mathrm{a}}<0.05$ vs. the TWEAK/EPC+AMI group. Fn 14 ,

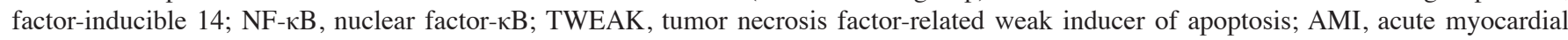
infarction; HW, heart weight; BW, body weight. LVEF, left ventricular ejection fraction; LVFS, left ventricular fractional shortening; LVIDd, left ventricular internal diameter at end-diastole; LVIDs, left ventricular internal diameter at end-systole; EPC, endothelial progenitor cell.

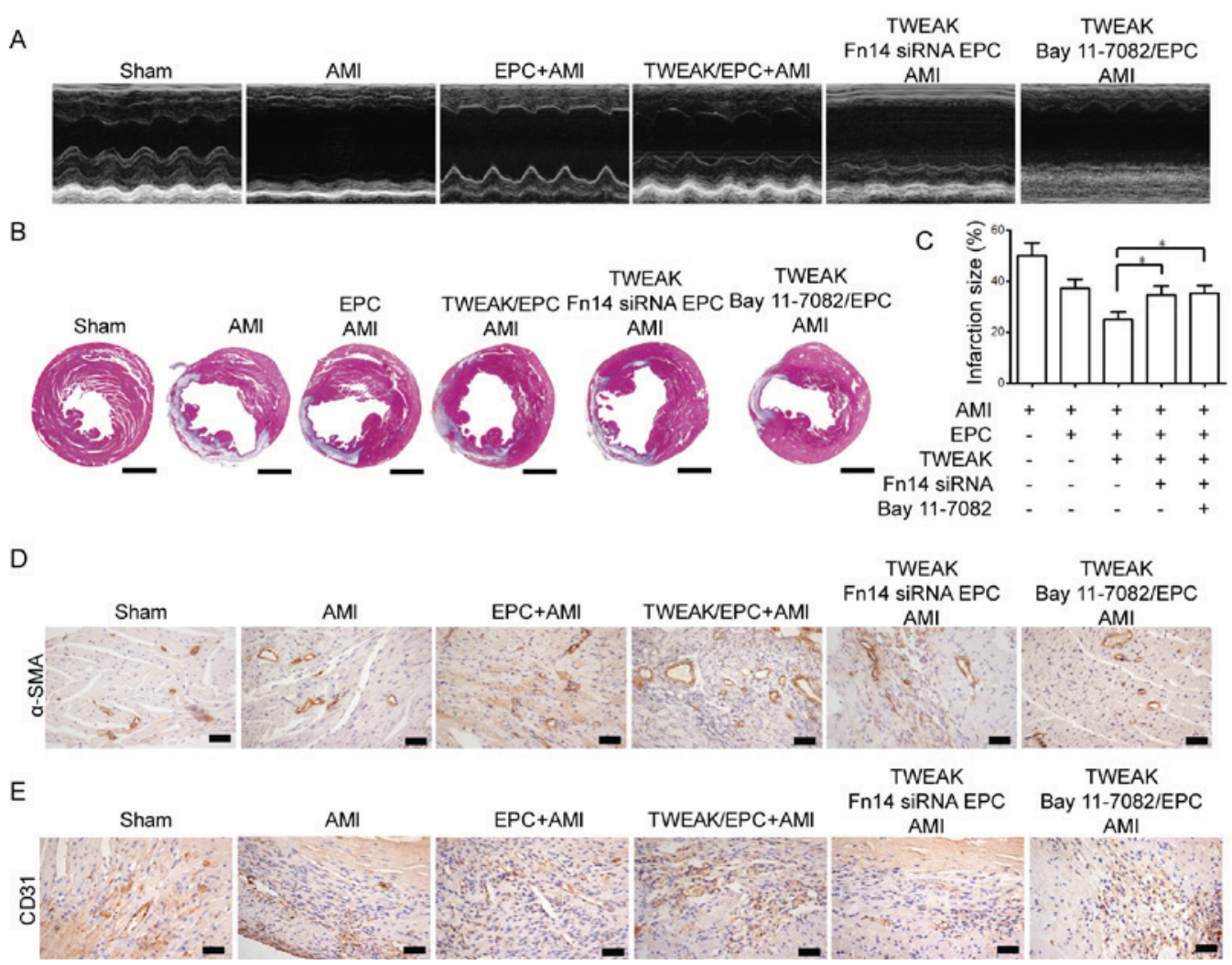

Figure 6. EPCs pretreated with TWEAK alleviate acute myocardial infarction via the Fn14 and NF- $\mathrm{B}$ pathway. Fn14-siRNA or Bay 11-7028 pretreated EPCs that subsequently received TWEAK were transplanted into mice with AMI. (A) Echocardiographic images of heart structure were then taken. (B) Masson's trichrome staining (blue) was performed to discriminate collagen fibers from murine heart tissue on histological slides (scale bar, $0.2 \mathrm{~cm}$ ). (C) Histological examination of murine AMI size (each, $\mathrm{n}=6$ ). ${ }^{*} \mathrm{P}<0.05$. (D) $\alpha$-SMA and (E) CD31 were measured using immunohistochemistry in each group (scale bar, $50 \mu \mathrm{m}$ ). EPCs, EPC, endothelial progenitor cells; TWEAK, tumor necrosis factor-related weak inducer of apoptosis; Fn14, fibroblast growth factor-inducible 14; siRNA, small interfering RNA; NF- $\mathrm{B}$, nuclear factor- $\mathrm{B}$; AMI, acute myocardial infarction; SMA, smooth muscle; CD, cluster of differentiation.

the regulation of TWEAK-mediated vasculogenesis remains to be elucidated.

In conclusion, the results of the present study demonstrated that the TWEAK/Fn14 mediated activation of NF- $\kappa$ B signaling promotes EPC viability, migration and vasculogenesis in vitro, as well as enhancing the protective effect of EPCs on injured murine AMI heart tissue in vivo. Thus, the present study indicated the beneficial effects and possible mechanisms of TWEAK in EPCs.

\section{Acknowledgements}

Not applicable.

\section{Funding}

The present study was supported by the National Nature Science Foundation of the People's Republic of China (grant no. 81400225 for ZS; grant no. 81470401 for YY; grant 
no. 81400219 for ZC; grant no. 81500204 for XP) and the Jiangsu Provincial Medical Youth Talent, Jiangsu, China (grant no. QNRC2016815).

\section{Availability of data and materials}

The analyzed data sets generated during the present study are available from the corresponding author on reasonable request.

\section{Authors' contributions}

ZLS conceived and designed the experiments. CWJ wrote the manuscript. CWJ, BL, ZPC, XDP and GLY performed all of the experiments. YRH analyzed the data. YYY and GSM contributed in collecting clinical tissue samples.

\section{Ethics approval and consent to participate}

The use of human samples was approved by the Ethics Committee of Zhongda Hospital, Medical School of Southeast University (Nanjing, China) and written informed consent was obtained from all patients prior to blood collection. The use of animals was approved by The Animal Care Committee of Southeast University (Nanjing, China).

\section{Patient consent for publication}

Patients provided written informed consent for the publication of any associated data from their blood samples.

\section{Competing interests}

The authors declare that they have no competing interests.

\section{References}

1. Reed GW, Rossi JE and Cannon CP: Acute myocardial infarction. Lancet 389: 197-210, 2017.

2. Korhonen MJ, Robinson JG, Annis IE, Hickson RP, Bell JS, Hartikainen J and Fang G: Adherence tradeoff to multiple preventive therapies and all-cause mortality after acute myocardial infarction. J Am Coll Cardiol 70: 1543-1554, 2017.

3. Nahrendorf M, Pittet MJ and Swirski FK: Monocytes: Protagonists of infarct inflammation and repair after myocardial infarction. Circulation 121: 2437-2445, 2010.

4. Cahill TJ, Choudhury RP and Riley PR: Heart regeneration and repair after myocardial infarction: Translational opportunities for novel therapeutics. Nat Rev Drug Discov 16: 699-717, 2017

5. Bossen C, Ingold K, Tardivel A, Bodmer JL, Gaide O, Hertig S, Ambrose C, Tschopp J and Schneider P: Interactions of tumor necrosis factor (TNF) and TNF receptor family members in the mouse and human. J Biol Chem 281: 13964-13971, 2006.

6. Urbich C and Dimmeler S: Endothelial progenitor cells: Characterization and role in vascular biology. Circ Res 95 343-353, 2004.

7. Tompkins BA, Natsumeda M, Balkan W and Hare JM: What is the future of cell-based therapy for acute myocardial infarction. Circ Res 120: 252-255, 2017.

8. Winkles JA: The TWEAK-Fn14 cytokine-receptor axis: Discovery, biology and therapeutic targeting. Nat Rev Drug Discov 7: 411-425, 2008.

9. Burkly LC: TWEAK/Fn14 axis: The current paradigm of tissue injury-inducible function in the midst of complexities. Semin Immunol 26: 229-236, 2014.
10. Roos A, Dhruv HD, Mathews IT, Inge LJ, Tuncali S, Hartman LK, Chow D, Millard N, Yin HH, Kloss J, et al: Identification of aurintricarboxylic acid as a selective inhibitor of the TWEAK-Fn14 signaling pathway in glioblastoma cells. Oncotarget 8: 12234-12246, 2017.

11. Hu G, Zeng W and Xia Y: TWEAK/Fn14 signaling in tumors. Tumour Biol 39: 1010428317714624, 2017.

12. Di Martino L, Dave M, Menghini P, Xin W, Arseneau KO, Pizarro TT and Cominelli F: Protective role for TWEAK/Fn14 in regulating acute intestinal inflammation and colitis-associated tumorigenesis. Cancer Res 76: 6533-6542, 2016.

13. Chorianopoulos E, Jarr K, Steen H, Giannitsis E, Frey N and Katus HA: Soluble TWEAK is markedly upregulated in patients with ST-elevation myocardial infarction and related to an adverse short-term outcome. Atherosclerosis 211: 322-326, 2010.

14. Mustonen E, Säkkinen H, Tokola H, Isopoussu E, Aro J, Leskinen H, Ruskoaho H and Rysä J: Tumour necrosis factor-like weak inducer of apoptosis (TWEAK) and its receptor Fn14 during cardiac remodelling in rats. Acta Physiol (Oxf) 199: $11-22,2010$

15. Garikipati VNS and Kishore R: Endothelial progenitor cells: procedure for cell isolation and applications. Methods Mol Biol 1553: 85-89, 2017

16. Ingram DA, Mead LE, Tanaka H, Meade V, Fenoglio A, Mortell K, Pollok K, Ferkowicz MJ, Gilley D and Yoder MC: Identification of a novel hierarchy of endothelial progenitor cells using human peripheral and umbilical cord blood. Blood 104: 2752-2760, 2004

17. Nagaya N, Nishikimi T, Yoshihara F, Horio T, Morimoto A and Kangawa K: Cardiac adrenomedullin gene expression and peptide accumulation after acute myocardial infarction in rats. Am J Physiol Regul Integr Comp Physiol 278: R1019-R1026, 2000.

18. Liao ZJ, Liang RS, Shi SS, Wang CH and Yang WZ: Effect of baicalin on hippocampal damage in kainic acid-induced epileptic mice. Exp Ther Med 12: 1405-1411, 2016.

19. Grimholt RM, Urdal P, Klingenberg O and Piehler AP: Rapid and reliable detection of $\alpha$-globin copy number variations by quantitative real-time PCR. BMC Hematol 14: 4, 2014.

20. Devarapu SK, Grill JF, Xie J, Weidenbusch M, Honarpisheh M, Vielhauer V, Anders HJ and Mulay SR: Tumor necrosis factor superfamily ligand mRNA expression profiles differ between humans and mice during homeostasis and between various murine kidney injuries. J Biomed Sci 24: 77, 2017.

21. Pelliccia F, Cianfrocca C, Rosano G, Mercuro G, Speciale G and Pasceri V: Role of endothelial progenitor cells in restenosis and progression of coronary atherosclerosis after percutaneous coronary intervention: a prospective study. JACC Cardiovasc Interv 3: 78-86, 2010.

22. Alobaid N, Alnaeb ME, Sales KM, Seifalian AM, Mikhailidis DP and Hamilton G: Endothelial progenitor cells and their potential clinical applications in peripheral arterial disease. Endothelium 12: 243-250, 2005.

23. Du F, Zhou J, Gong R, Huang X, Pansuria M, Virtue A, Li X, Wang $\mathrm{H}$ and Yang XF: Endothelial progenitor cells in atherosclerosis. Front Biosci (Landmark Ed) 17: 2327-2349, 2012

24. Schier R, El-Zein R, Cortes A, Liu M, Collins M, Rafat N, Teschendorf P, Wu HK, Heymach J, Mehran R and Riedel B: Endothelial progenitor cell mobilization by preoperative exercise: A bone marrow response associated with postoperative outcome. Br J Anaesth 113: 652-660, 2014.

25. Gong X, Shao L, Fu YM and Zou Y: Effects of olmesartan on endothelial progenitor cell mobilization and function in carotid atherosclerosis. Med Sci Monit 21: 1189-1193, 2015.

26. Xu L, Duda DG, di Tomaso E, Ancukiewicz M, Chung DC, Lauwers GY, Samuel R, Shellito P, Czito BG, Lin PC, et al: Direct evidence that bevacizumab, an anti-VEGF antibody, up-regulates SDF1 $\alpha$, CXCR4, CXCL6 and neuropilin 1 in tumors from patients with rectal cancer. Cancer Res 69: 7905-7910, 2009.

27. Cho BS, Zeng Z, Mu H, Wang Z, Konoplev S, McQueen T, Protopopova M, Cortes J, Marszalek JR, Peng SB, et al: Antileukemia activity of the novel peptidic CXCR4 antagonist LY2510924 as monotherapy and in combination with chemotherapy. Blood 126: 222-232, 2015.

28. Stellos K and Gawaz M: Platelets and stromal cell-derived factor-1 in progenitor cell recruitment. Semin Thromb Hemost 33: 159-164, 2007.

29. Tilling L, Chowienczyk P and Clapp B: Progenitors in motion: Mechanisms of mobilization of endothelial progenitor cells. Br J Clin Pharmacol 68: 484-492, 2009. 
30. Oh IY, Yoon CH, Hur J, Kim JH, Kim TY, Lee CS, Park KW, Chae IH, Oh BH, Park YB and Kim HS: Involvement of E-selectin in recruitment of endothelial progenitor cells and angiogenesis in ischemic muscle. Blood 110: 3891-3899, 2007.

31. Chavakis E, Aicher A, Heeschen C, Sasaki K, Kaiser R, El Makhfi N, Urbich C, Peters T, Scharffetter-Kochanek K, Zeiher AM, et al: Role of beta2-integrins for homing and neovascularization capacity of endothelial progenitor cells. J Exp Med 201: 63-72, 2005.

32. Burkly LC: Regulation of tissue responses: The TWEAK/Fn14 pathway and other TNF/TNFR superfamily members that activate non-canonical NFkB signaling. Front Immunol 6: 92, 2015.

33. Chorianopoulos E, Heger T, Lutz M, Frank D, Bea F, Katus HA and Frey N: FGF-inducible 14-kDa protein (Fn14) is regulated via the RhoA/ROCK kinase pathway in cardiomyocytes and mediates nuclear factor-kappaB activation by TWEAK. Basic Res Cardiol 105: 301-313, 2010.

34. Yin J, Liu YN, Tillman H, Barrett B, Hewitt S, Ylaya K, Fang L, Lake R, Corey E, Morrissey C, et al: AR-regulated TWEAK-FN14 pathway promotes prostate cancer bone metastasis. Cancer Res 74: 4306-4317, 2014.

35. Jarr KU, Eschricht S, Burkly LC, Preusch M, Katus HA, Frey N and Chorianopoulos E: TNF-like weak inducer of apoptosis aggravates left ventricular dysfunction after myocardial infarction in mice. Mediators Inflamm 2014: 131950, 2014.

36. Chen HN, Wang DJ, Ren MY, Wang QL and Sui SJ: TWEAK/Fn14 promotes the proliferation and collagen synthesis of rat cardiac fibroblasts via the NF- $\kappa$ B pathway. Mol Biol Rep 39: 8231-8241, 2012.
37. Sanz AB, Sanchez-Niño MD, Izquierdo MC, Jakubowski A, Justo P, Blanco-Colio LM, Ruiz-Ortega M, Egido J and Ortiz A: Tweak induces proliferation in renal tubular epithelium: A role in uninephrectomy induced renal hyperplasia. J Cell Mol Med 13: 3329-3342, 2009.

38. Maeng YS, Choi YJ and Kim EK: TGFBIp regulates differentiation of EPC (CD133 ${ }^{+} \mathrm{c}^{-\mathrm{kit}^{+} l i n}{ }^{-}$cells) to EC through activation of the Notch signaling pathway. Stem Cells 33: 2052-2062,2015.

39. Singh RP, Dhanalakshmi S, Agarwal C and Agarwal R: Silibinin strongly inhibits growth and survival of human endothelial cells via cell cycle arrest and downregulation of survivin, Akt and $\mathrm{NF}-\kappa \mathrm{B}$ : Implications for angioprevention and antiangiogenic therapy. Oncogene 24: 1188, 2005.

40. Duan H, Chen L, Qu L, Yang H, Song SW, Han Y, Ye M, Chen W, He X and Shou C: Mycoplasma hyorhinis infection promotes $\mathrm{NF}-\kappa \mathrm{B}$-dependent migration of gastric cancer cells. Cancer Res 74: 5782-5794, 2014.

41. Tirziu D, Jaba IM, Yu P, Larrivée B, Coon BG, Cristofaro B, Zhuang ZW, Lanahan AA, Schwartz MA, Eichmann A and Simons M: Endothelial nuclear factor- $\kappa$ B-dependent regulation of arteriogenesis and branching. Circulation 126: 2589-2600, 2012.

This work is licensed under a Creative Commons Attribution-NonCommercial-NoDerivatives 4.0 International (CC BY-NC-ND 4.0) License. 